\title{
Delayed detection of subcutaneous emphysema following routine endotracheal intubation
} -A case report-

\author{
Youn Yi Jo ${ }^{1}$, Woo Young Park ${ }^{1}$, Eunkyeong $\mathrm{Choi}^{1}$, Bon Nyeo Koo ${ }^{1,2}$, and Hae Keum Kil ${ }^{1,2}$ \\ ${ }^{1}$ Department of Anesthesiology and Pain Medicine, ${ }^{2}$ Anesthesia and Pain Research Institute, Yonsei University College of Medicine, \\ Seoul, Korea
}

A tracheal intubation-related tracheobronchial rupture is a relatively rare complication. We report a case of tracheobronchial rupture after single lumen endotracheal intubation. Twenty four hours after extubation of an endotracheal tube, subcutaneous emphysema developed on the patient's neck. A pneumomediastinum was also detected by computerized tomography (CT). The patient recovered uneventfully after conservative management. (Korean J Anesthesiol 2010; 59: 220-223)

Key Words: Delayed detection, Intubation, Subcutaneous emphysema.

Tracheobronchial rupture is considered a life threatening condition that occurs most commonly after blunt trauma to the neck and chest, but rarely after tracheal intubation. The precise mechanism is unclear. However, the most probable explanation is a direct laceration from the endotracheal tube tip caught in a fold of a flaccid posterior tracheal membrane while advancing the tube [1]. We report the delayed detection of subcutaneous emphysema after routine endotracheal intubation.

\section{Case Report}

A 62-year-old man (weight, $59.5 \mathrm{~kg}$; height, $162 \mathrm{~cm}$; BMI, $22.7 \mathrm{~kg} / \mathrm{m}^{2}$ ) was scheduled to undergo a subtotal gastrectomy with gastrojejunostomy. The patient had been diagnosed with hypothyroidism one year earlier and had been prescribed medication since then. No specific abnormal laboratory results were noted on the preoperative evaluation except a first degree AV block on the electrocardiograph.

Midazolam $2 \mathrm{mg}$ was administered i.m. as premedication 30 minutes before anesthesia. In the operating room, the patient was monitored by an electrocardiogram, a noninvasive blood pressure monitor and pulse oximetry. The baseline blood pressure, heart rate, and $\mathrm{SpO}_{2}$ were within the normal range. Before induction, epidural catheterization was performed at the T6-7 interspace with a paramedian approach for continuous postoperative analgesia. There were no questionable signs suggesting a pneumothorax or pneumomediastinum during epidural catheterization. Anesthesia was induced with $100 \mathrm{mg}$

Received: August 24, 2009. Revised: 1st, September 14, 2009; 2nd, September 30, 2009. Accepted: October 27, 2009.

Corresponding author: Hae Keum Kil, M.D., Department of Anesthesiology and Pain Medicine, Yonsei University College of Medicine, Sinchondong, Seodaemun-gu, Seoul 120-752, Korea. Tel: 82-2-2228-2414, Fax: 82-2-312-7185, E-mail: hkkil@yuhs.ac

(c) This is an open-access article distributed under the terms of the Creative Commons Attribution Non-Commercial License (http:// creativecommons.org/licenses/by-nc/3.0/), which permits unrestricted non-commercial use, distribution, and reproduction in any medium, provided the original work is properly cited. 
of propofol and $40 \mu \mathrm{g}$ of remifentanil. Facial mask ventilation was made easy with $100 \% \mathrm{O}_{2}$. After an intravenous injection of $50 \mathrm{mg}$ rocuronium, tracheal intubation was performed using a single lumen internal diameter (ID) $8.0 \mathrm{~mm}$ tube (Mallinckrodt medical. high volume low pressure. Athlone. Ireland) in one attempt without difficulty. The laryngeal grade was 1 and the tracheal tube was passed through trachea without resistance. The tube was fixed $23 \mathrm{~cm}$ from the level of the incisors and the cuff was inflated with $4 \mathrm{ml}$ of air as a minimal volume to prevent a circle leak in this patient. Bilateral breath sounds were confirmed by auscultation. Anesthesia was maintained with isoflurane in air $/ \mathrm{O}_{2}\left(\mathrm{FiO}_{2}=0.5\right)$ and supplemental continuous infusion of remifentanil. A nasogastric decompressive tube was not inserted into this patient. No other venous access including central venous line was made. The subtotal gastrectomy with gastroduodenostomy (Billoth I) under the diaphragm proceeded without an event. At the end of surgery, all anesthetic agents were discontinued and the residual neuromuscular blockade was reversed with pyridostigmine and glycopyrrolate. The tracheal tube was removed when the patient responded to verbal commands and showed sufficient spontaneous respiration and neuromuscular function (as ascertained by the nerve stimulator). There were no tinged signs of blood or tissue-like material on the removed tube. The patient remained in the post-anesthetic care unit (PACU) for 30 minutes event free and was then transferred to the general ward. During the 24 hour postoperative period, the patient's vital signs were stable without any specific incidents. On postoperative day 1 , the patient complained of discomfort on the left lateral side of the neck without any dysphagia or dyspnea. On palpation, diffuse crepitus was felt on that site of the neck but no definite swelling was detected. Pulse oximetry revealed an oxygen saturation of $91 \%$ under room air breathing. Oxygen with a flow rate of $3 \mathrm{~L} / \mathrm{min}$ was provided through a nasal cannula. The

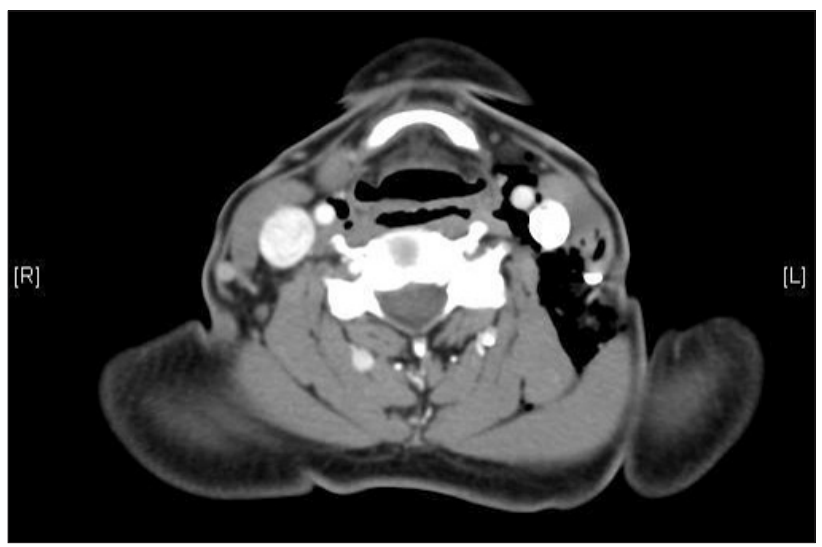

Fig. 1. Axial computed tomogram of the neck showing extensive air on the left side of trachea and retropharyngeal space. patient had already been placed on nil orally and intravenous antibiotics administration due to surgery. Arterial gas analysis before applying the oxygen showed the following: $\mathrm{pH}$ 7.44, $\mathrm{PaO}_{2} 74.4 \mathrm{mmHg}, \mathrm{PaCO}_{2} 34.2 \mathrm{mmHg}$ and $95.8 \%$ of $\mathrm{SaO}_{2}$. Neck CT (Fig. 1), chest CT (Fig. 2) and chest x-ray revealed emphysema of the left neck (Fig. 3), a retropharyngeal space and a pneumomediastinum. The patient was observed closely with an electrocardiograph and pulse oximetry. The patient showed no specific signs or symptoms over the subsequent 24 hours, and the oxygen saturation was maintained at 99-100\%. Antibiotics were used for only two days, and a diet was also started. On postoperative day 6, the emphysema of the neck

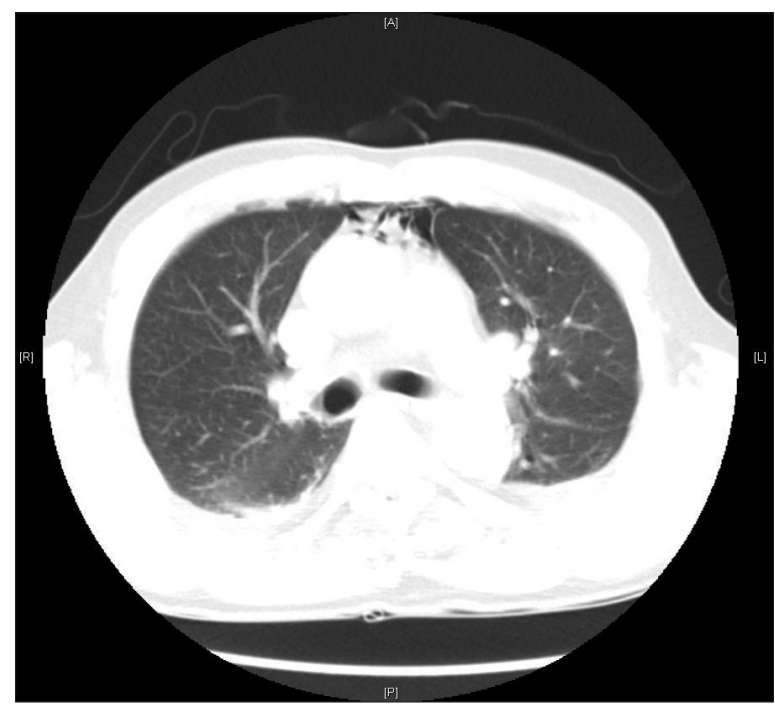

Fig. 2. Axial computed tomogram of the mediastinum showing pneumomediastinum on anterior mediastinum.

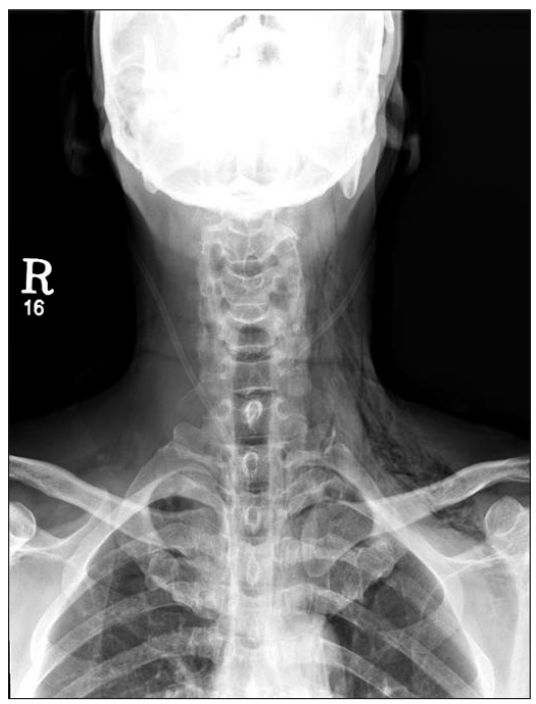

Fig. 3. Neck radiograph showing a subcutaneous emphysema on left side of neck. 
and retraopharynx had almost resolved, but a small amount of air still remained in the mediastinum (Fig. 4). He had an uneventful recovery and was discharged on postoperative day 8 . Five days after discharge, the neck AP/lateral x-ray still showed slight emphysematous signs. However, the patient did not feel any discomfort.

\section{Discussion}

Subcutaneous emphysema on the head, neck or upper trunk with a pneumomediastinum is rare after general endotracheal anesthesia [2]. The previously reported factors contributing to this event have been explained by two mechanisms. First, a tear in the tracheal mucosa may occur during passage of the endotracheal tube or by overinflation of the cuff of the endotracheal tube [3]. Second, there may be a congenital dehiscence in the mucosa like a bullae, clefts or laryngocoeles [4]. In our case, tracheal intubation was performed without difficulty in the first attempt using the usual tube. The inflated cuff pressure was not checked, but the cuff was inflated with $4 \mathrm{ml}$ of air, and the degree of inflation was checked with soft feeling in the usual manner.

Several studies reported catastrophic consequences of endotracheal tube cuff over-inflation, such as rupture of the trachea [5-7]. Sencupta et al. [8] reported a linear relationship between the air volume and cuff pressure. Moreover, the air volume required to maintain a cuff pressure of $20 \mathrm{cmH}_{2} \mathrm{O}$ was $2.5-$ $4.1 \mathrm{ml}$ (mean $=3.0 \mathrm{ml}$ ) on $8.0 \mathrm{~mm}$ I.D. They suggested that the injected volumes of 2-4 ml normally produce cuff pressures between 20 and $30 \mathrm{cmH}_{2} \mathrm{O}$ independent of the tube size for

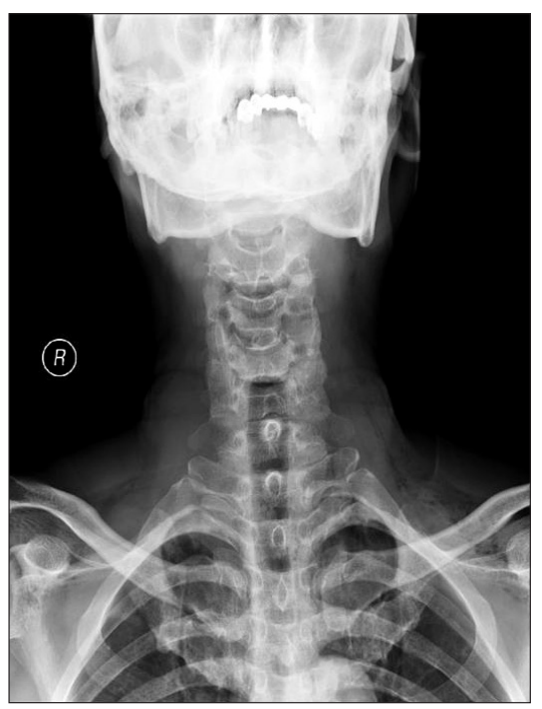

Fig. 4. Neck radiograph showing an improvement of subcutaneous emphysema on left lateral side of neck compared with Fig. 3, but still slightly remained. the same type of tube. Therefore, in our case, it is possible that the cause of the pneumomediastinum and emphysema might be related to tracheal rupture due to overinflation of the tube cuff. The possibility of tracheal rupture employing a reused endotracheal tube has been suggested [9]. However, new endotracheal tube without stylet was used in this case.

The clinical symptoms of tracheobroncheal rupture (TBR) mostly appear during the mechanical ventilation during anesthesia, and a large number of injuries have been diagnosed shortly after intubation. Nevertheless, detectable symptoms and signs may also be observed after a delayed postoperative period [10]. In the present case, the symptom of neck discomfort only was detected after 24 hours. It is believed that the delayed emphysema occurred with a possible small tear of the tracheal mucosa, allowing a slow and gradual leakage of a small amount of air.

Iatrogenic TBR should be differentiated from tracheobronchial injuries with a traumatic origin because it has different mechanisms leading to a different morphological appearances and therapeutic options [11]. Iatrogenic TBR usually presents as longitudinal lacerations of the posterior tracheal wall, either centrally located, or laterally, such that the membranous wall is avulsed from its cartilaginous insertion [12,13]. Rigid tracheobronchoscopy is needed to confirm a tracheal mucosa laceration and plan the optimal treatment [14]. CT is necessary only in some cases of suspicious of mediastinal bleeding or mediastinal emphysema, which are not visible by conventional chest $\mathrm{x}$-rays. In our case, the lesion was not identified by bronchoscopy, but a posterolateral wall laceration of trachea was indicated by CT (Fig. 5). TBR is sometimes considered life

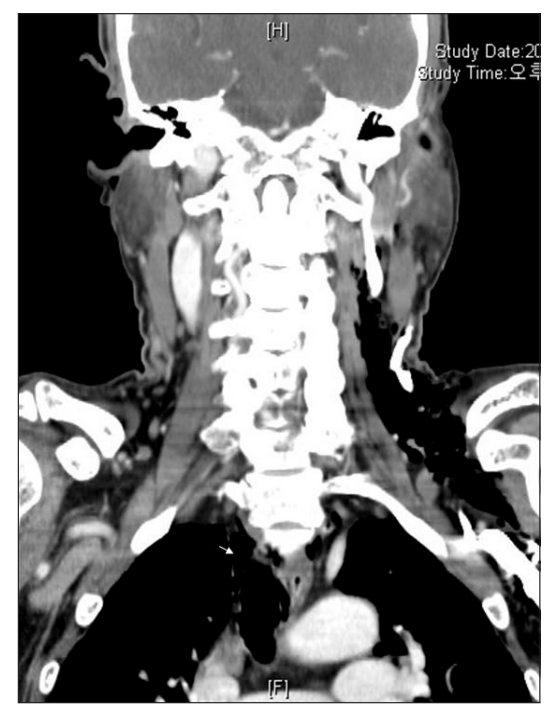

Fig. 5. Computed tomogram of the neck showing a disruption of tracheobroncheal wall. 
threatening because subcutaneous emphysema that expands in the neck can compress the trachea and major blood vessels. Moreover, venous compression from a pneumomediastinum can result in venous congestion that could decrease the cardiac output leading to death. The other major complication is infection. The oropharyngeal secretions can run down and contaminate the surrounding tissues resulting in a cervical and mediastinal infection and abscess formation [15]. Surgical repair is indicated if either septic conditions or airway compromise develops. Conservative management, such as close monitoring, keeping nil orally and intravenous broad spectrum antibiotics administration, is indicated when there is no clinical deterioration [3].

To reduce the complication of tracheal rupture, multiple vigorous attempts of intubation should be avoided. Instead, appropriate intubation-aid devices should be used. If repositioning of the tube is required, the tube must be moved with cuff deflation to avoid vigorous cough [2].

Although tracheal intubation-related airway ruptures are rare, the severity of this problem should not be underestimated as it is associated with mortality. An immediate evaluation and proper management is mandatory when there is the slightest suspicion of TBR.

\section{References}

1. Conti M, Pougeoise M, Wurtz A, Porte H, Fourrier F, Ramon P, et al. Management of postintubation tracheobronchial ruptures. Chest 2006; 130: 412-8.

2. Kim BJ, Kim JW, Shin DY, Hong KH. Tracheal rupture during the use of Robertshaw double-lumen endotracheal tube for one lung ventilation. A case report. Korean J Anesthesiol 1997; 32: 131-4.

3. Ross HM, Grant FJ, Wilson RS, Burt ME. Nonoperative management of tracheal laceration during endotracheal intubation. Ann Thorac
Surg 1997; 63: 240-2.

4. Chiu CL, Ong GS. Subcutaneous emphysema and pneumomediastinum after endotracheal anaesthesia. Ann Acad Med Singapore 2000; 29: 256-8.

5. Gottschalk A, Burmeister MA, Blanc I, Schulz F, Standl T. Rupture of the trachea after emergency endotracheal intubation. Anasthesiol Intensivmed Notfallmed Schmerzther 2003; 38: 59-61.

6. Striebel HW, Pinkwart LU, Karavias T. Tracheal rupture caused by overinflation of endotracheal tube cuff. Anaesthesist 1995; 44: 1868.

7. Luna CM, Legarreta G, Esteva H, Laffaire E, Jolly EC. Effect of tracheal dilatation and rupture on mechanical ventilation using a low-pressure cuff tube. Chest 1993; 104: 639-40.

8. Sengupta P, Sessler DI, Maglinger P, Wells S, Vogt A, Durrani J, et al. Endotracheal tube cuff pressure in three hospitals and the volume required to produce an appropriate cuff pressure. BMC Anesthesiol 2004; 4 : 8.

9. Seo JW, Ha JH, Kwak KH, Jeon YH, Kim SO. Tracheal ruture after the use of reused high volume-low pressure endotracheal tube-a case report. Korean J Anesthesiol 2007; 52: 123-6.

10. Hofmann HS, Rettig G, Radke J, Neef H, Silber RE. Iatrogenic ruptures of the tracheobronchial tree. Eur J Cardiothorac Surg 2002; 21: 649-52.

11. Lampl L. Tracheobronchial injuries. Conservative treatment. Interact Cardiovasc Thorac Surg 2004; 3: 401-5.

12. Marty-Ane CH, Picard E, Jonquet O, Mary H. Membranous tracheal rupture after endotracheal intubation. Ann Thorac Surg 1995; 60: 1367-71.

13. Massard G, Rouge C, Dabbagh A, Kessler R, Hentz JG, Roeslin N, et al. Tracheobronchial laceration after intubation and tracheostomy. Ann Thorac Surg 1996; 61: 1483-7.

14. Luchini L, Brega M, Giani I, Cosimini P, Santini L, Giunta G. Tracheal rupture a complication of orotracheal intubation. Minerva Anestesiol 2002; 68: 621-5.

15. Watters KF, Lacy PD, Walsh RM. Massive subcutaneous emphysema following routine endotracheal intubation. J Laryngol Otol 2003; 117: 899-901. 